\title{
Analysis of land use and land cover spatial pattern based on Markov chains modelling
}

\author{
Jafar Mirkatouli ${ }^{1}$, Ali Hosseini ${ }^{2^{*}}$ and Abdolhamid Neshat ${ }^{3}$
}

\begin{abstract}
Background: Population growth and the expansion of cities together with an increase in environmental pollution from human activity create non-principled changes in vegetative cover and land use in forestland built-up areas and agricultural land and increase the exertion of non-principled land productivity methods.

Methods: In this study, the proximity to and the amount of agricultural and forestland were used in the analysis and modeling of the land use changes. The probability of the conversion of agricultural and forestland to built-up areas use was modeled using the Markov chain.

Results: The results indicate that the southern part of Gorgan ranked first in likelihood of the land use/land cover (LULC) change. It is necessary to implement procedures to control the change of high-grade agricultural land and Naharkhoran forestland to built-up areas.

Conclusions: It is clear that without attention to planning for protective procedures, the trend toward changing agricultural and forestland to built-up areas will continue and have adverse effects on the regional environment.

Keywords: Land Use/Land Cover (LULC); Changes detection; Markov chains; Urban sprawl; Geographical Information System (GIS)
\end{abstract}

\section{Introduction}

Rapid urbanization has led to dramatic changes in land use practices. The growth can expand new residential developments and damage the surrounding areas and lead to urban sprawl (Torre et al., 2014; Nanda and Yeh, 2014; Hosseini et al., 2010). The incompatibility between the amount of land for inhabitants of agricultural areas around a city and that for urban inhabitants is the obvious result of such change (Palermo, 2014). Agricultural land surrounding cities play an important role in providing food security and income for the rapidly-growing urban population (Pathirana et al. 2014). The expansion of the ecological footprint of cities challenges the foundations of sustainable development.

Land use/land cover (LULC) change is important for social, economic and regional development and environmental change (Chen et al., 2013; Barsimantov \& Navia Antezana, 2012; Zhang et al., 2010; Klosterman, 2008). Urban management must develop urban regions to meet

\footnotetext{
* Correspondence: a.hosseini@ut.ac.ir

${ }^{2}$ Department of Geography and Urban Planning, University of Tehran, Tehran 1417854151, Iran

Full list of author information is available at the end of the article
}

public needs and benefit the current and future residents of cities and the areas surrounding them. Tools should be provided for the regional control of cities (Carvalho Ribeiro et al., 2013). Traditional methods and large-scale precision land surveying on the ground is expensive and time-consuming and, in some cases, impossible. New tools and methods are necessary in such cases. Remote sensing technology offers high spatial resolution and is a valuable mechanism for the monitoring, diagnosis, identification and zoning of natural resources, especially in land-use mapping (Tan et al., 2015). Remote sensing digital images provide updated information and comprehensive views and use different parts of the electromagnetic spectrum to record characteristics of the area under study (Antwi et al., 2014; Fonji and Taff, 2014). The repetitive land covers, speed and variety of data types are of great value (Mabwoga and Thukral, 2014).

Remote sensing is the major source of data and is used in the study of areas with urban or manmade characteristics, landscapes and natural environments (Peled and Gilichinsky, 2013; Ye and Fang, 2011; Bhatta et al., 2010; Pelorosso et al., 2009). In combination with GIS techniques such as the 
Markov chain model, it provides a device for monitoring spatial development to increase understanding of current trends of development. It can be used to estimate development of a city and to implement necessary control measures. Understanding the proportion of land use and its changes over time is essential for planning and development of control measures.

\section{Study area}

Gorgan is the provincial capital of Golestan province and a major center of economic, social and cultural life in the province and in Iran. The National Physical Plan has shown that in the past decade, the urban network of Gorgon, like the rest of the country, is population absorbent and vulnerable to improper development of urban spaces (Mirali-Katouli, 2002).

Gorgan sits in the western part of the province at an average altitude of $155 \mathrm{~m}$. It is located at $24^{\circ} 54^{\prime}$ east longitude and $49^{\circ} 36^{\prime}$ north latitude on the northern slopes of the Alborz mountain range. The area south of Gorgan overlooks forested mountains adjacent to the major highway to the north. The growth and expansion of the city is greater along the highway. The heights to the south and southwest of the city are major physical barriers to the development of the city in these directions (Figure 1) (Varasteh Moradi 1997).

The Gorgan and Gonbad plains are major agricultural regions and the city is expanding into the fertile farm land. The dense forests are subject to heavy rainfall that has leached salinity from the soil, which makes it excellent for farming (Shahkohi, 1999). The forestland soil in these areas is composed of humus and is quickly used in cleared areas. Some forestland is composed of loess and are appropriate are for pasture land. The alluvial plains contain the remnants of torrential rivers and features clay soil in some areas. Soil salinity has gradually increased in this area and agricultural products are cultivated using irrigation. The slope of these lands is less than 1\% (Gorgan Watershed 2001).

Studies of the Gorgan plain in 1974 show a population of 74164 ; by 1994 , population was 180726 . The city population in 1976 was 88,033 , increased during 1996 to 1986 to 139430 , was 188710 in 2006 and is currently more than 269226 (Plan and Architect Iran Consulting Engineers, 2006). Study of population changes in the city shows that of the 80,516 increase in population between 1996 and 2006, 58,219 were immigrants. It is estimated that the population increase of the city of Gorgan will

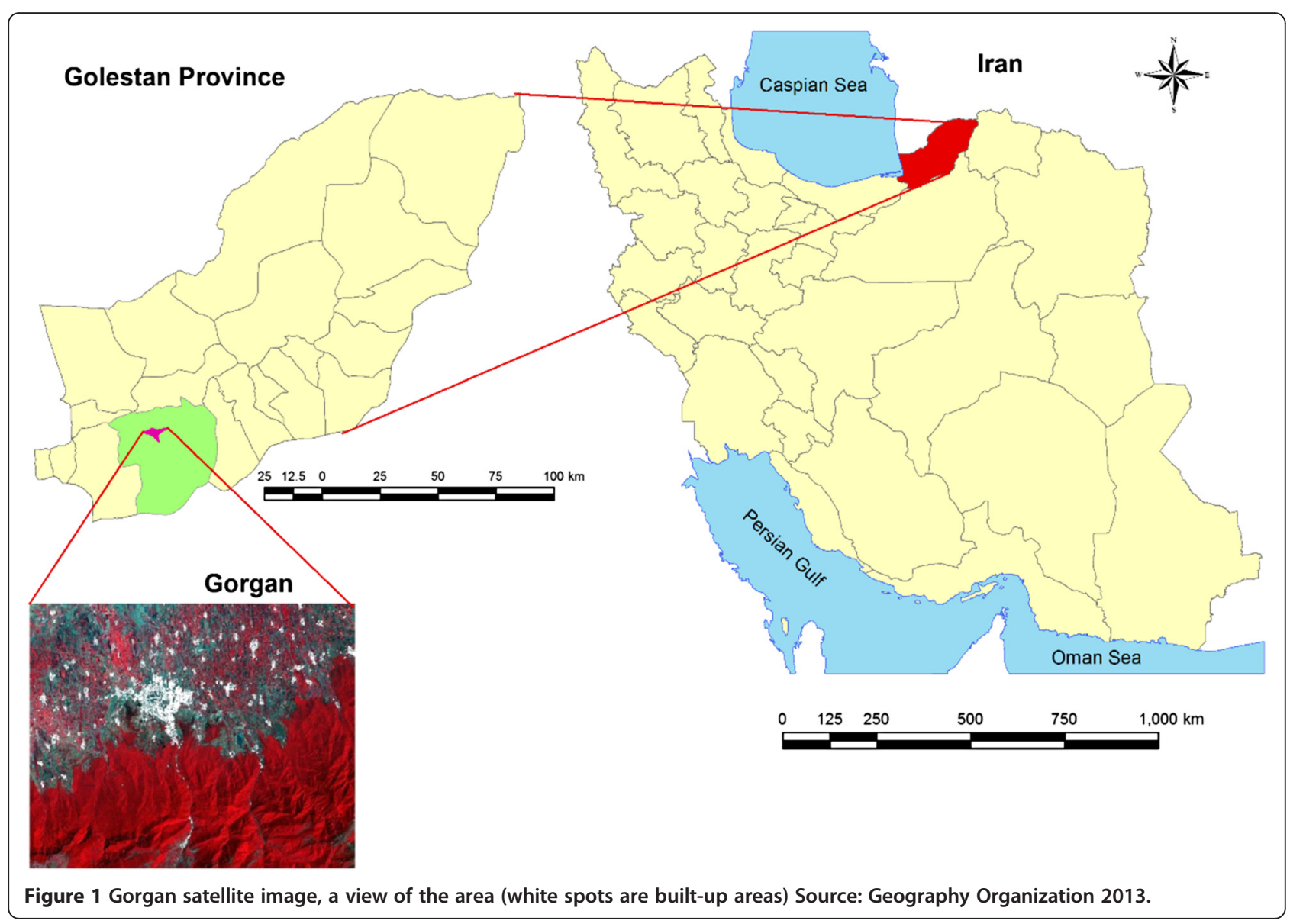


continue in the future (Iran Statistical Center, 2013). A realistic assessment is that it will reach 341,858 by 2023 . It is clear that with such population growth will place a large number of new demands for built-up areas.

\section{Methodology}

A comparison of the post-classification method was used to measure change the level of LULC types, especially residential and built-up areas. Land use was classified into six types. This method minimizes measurement and environmental atmospheric effects in the multi-temporal images and provides a complete matrix of the change information. The present study provides a map of the severity of change (change or lack of change).

A combination of methods for image subtraction and principal components analysis and the division of images and principal components analysis were used to achieve exact results since the application of only one method limits the precision of the results. Principal components analysis cannot be considered for the purpose of research because information on LULC change will not appear for only one component (Trincsi et al., 2014; Gong et al. 2015).

Maps of LULC change were developed using a combination of methods and by overlapping of different information layers. TM and ETM images from the study area in 1991 and 2013 years were first prepared. Then a topographic map of the area was corrected and coordinated using selected ground control points (37 points). Atmospheric changes were rectified using the atmospheric and topographic correction (ATCOR3) method (Balthazar et al., 2012) and had a root mean square error (RMSE) of 0.33. Interpolation of the images was performed using the nearest neighbor algorithm. Examples of different types of the LULC classes (forestland, agriculture, built-up areas, unused land and other lands) were specified on area images and classified using spectral angle mapping. This method uses the angle between components or spectral members for classification and the angles of individual pixels relative to the position of the training pixels according to Eq (1):

$$
\cos \theta=\frac{\sum_{i} \text { ripi }}{\sqrt{\sum_{i}^{n} r i^{2} \sum_{i}^{n} p i^{2}}}
$$

where $\theta$ is the angle between the reference spectral member and the intended spectral member; $r$ is the reference spectral value; and $p$ is the intended pixel spectral value (Lillesand et al., 2008); Schott, 2007; Richards and Jia 2006).

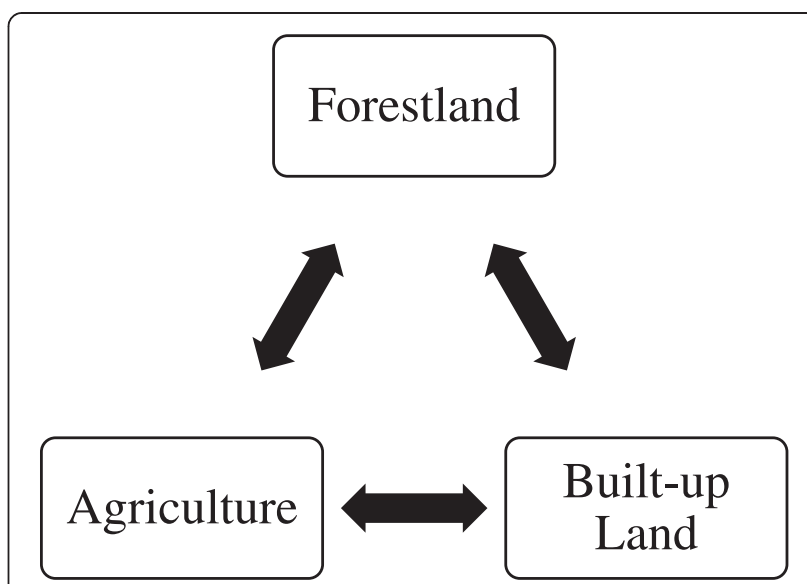

Figure 2 Six modes of conversion for forestland, built areas and agriculture land use.

\section{Markov chain analysis}

Markov properties or characteristics are characteristics of random processes in which the conditional probability of a future event depends only on the most recent incident (the present event) and not on past events. In mathematics where $X(t)$, and $t>0$ is a stochastic process with the Markov property (Gong et al., 2015; Aurbacher and Dabbert, 2011; Eksler, 2008), then Eq.2:

$$
\begin{aligned}
\operatorname{Pr}[X(t+h) & =y \mid X(s)=X(s), \forall s \leq t] \\
& =\operatorname{Pr}[X(t+h)=y \mid X(t) \\
& =X(t)], \forall h>0 .
\end{aligned}
$$

In discrete time for a process like $\left\{X_{n} \mid n \in N\right\}$ with Markov properties, the result is $\{P\{X n+\mid 1 X n=x n\}$. Such processes are usually addressed using a Markov chain (Feitosa et al., 2011). Markov chains model probable forecasts of stochastic processes where the future state of a system depends on its current state (Thompson \& Waddington, 2014; Guan et al., 2011).

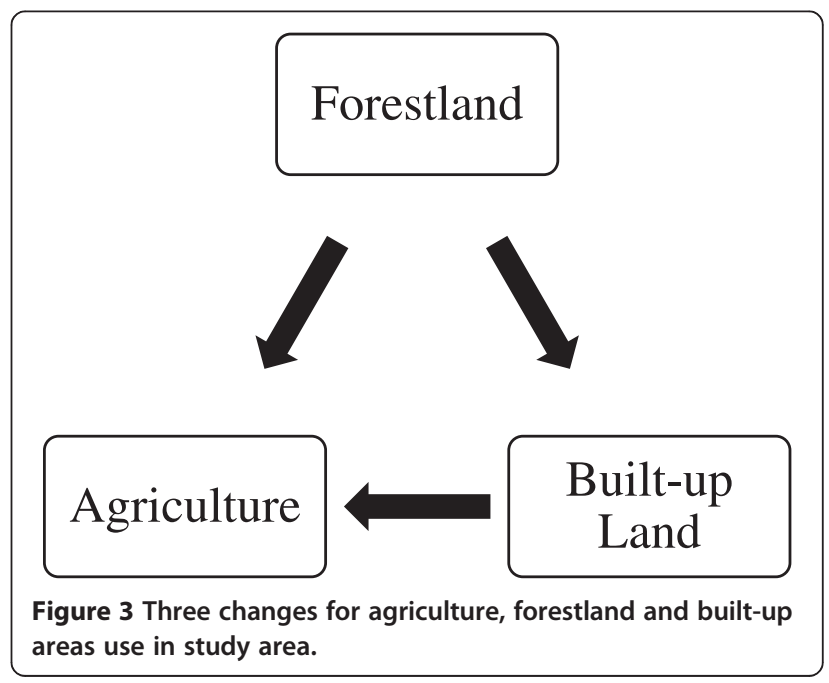


Table 1 Comparison of the classified images of 1991 and 2013

\begin{tabular}{|c|c|c|c|c|c|c|c|}
\hline \multicolumn{8}{|l|}{1991} \\
\hline 2013 & Forestland & Agriculture & Built-up areas & Unused land & Jungle park & Other lands & Sum \\
\hline Forestland & 2012.20 & 3.93 & 0.49 & 1.57 & 0.0 & 0.61 & 2018.80 \\
\hline Agriculture & 253.57 & 1784.75 & 0.00 & 1415.16 & 9.4 & 1.05 & 3463.93 \\
\hline Built-up areas & 51.47 & 768.38 & 1968.34 & 2176.64 & 0.0 & 12.30 & 4977.13 \\
\hline Unused land & 372.31 & 558.24 & 0.00 & 1062.03 & 1.27 & 1.54 & 1995.39 \\
\hline Jungle park & 35.48 & 9.34 & 0.87 & 114.91 & 46.52 & 1.14 & 208.26 \\
\hline Other lands & 0.84 & 4.23 & 0.12 & 3.06 & 0.10 & 6784.42 & 6792.77 \\
\hline Sum & 2725.87 & 3128.87 & 1969.82 & 4773.37 & 57.29 & 6801.06 & 19456.28 \\
\hline
\end{tabular}

A first-order Markov chain is a suitable statistical model to evaluate and predict two-state events (occurrence or non-occurrence) which can be used to provide a clear framework for ideas and data and the combination and modulation of them. It can be used to predict and evaluate different scenarios for LULC change, to formulate parameters and variables and perceive patterns and their correlations (Yang et al., 2012; Kamusoko et al., 2009). The first-order Markov model assumes that, to predict the state of a system at time $t+1$, it is sufficient to know the state at time $t$.

The model is based on the transfer matrix $(p)$, which indicates the possibility of change of two types of cover ( $i$ and $j$ ) relative to one another over a period of time. This matrix is calculated by comparing the classification of the images from 1991 and 2013. The future state of a system at $t+1$ can be calculated through the transfer matrix at the current state of the system $(x t)$ as $t+1$.

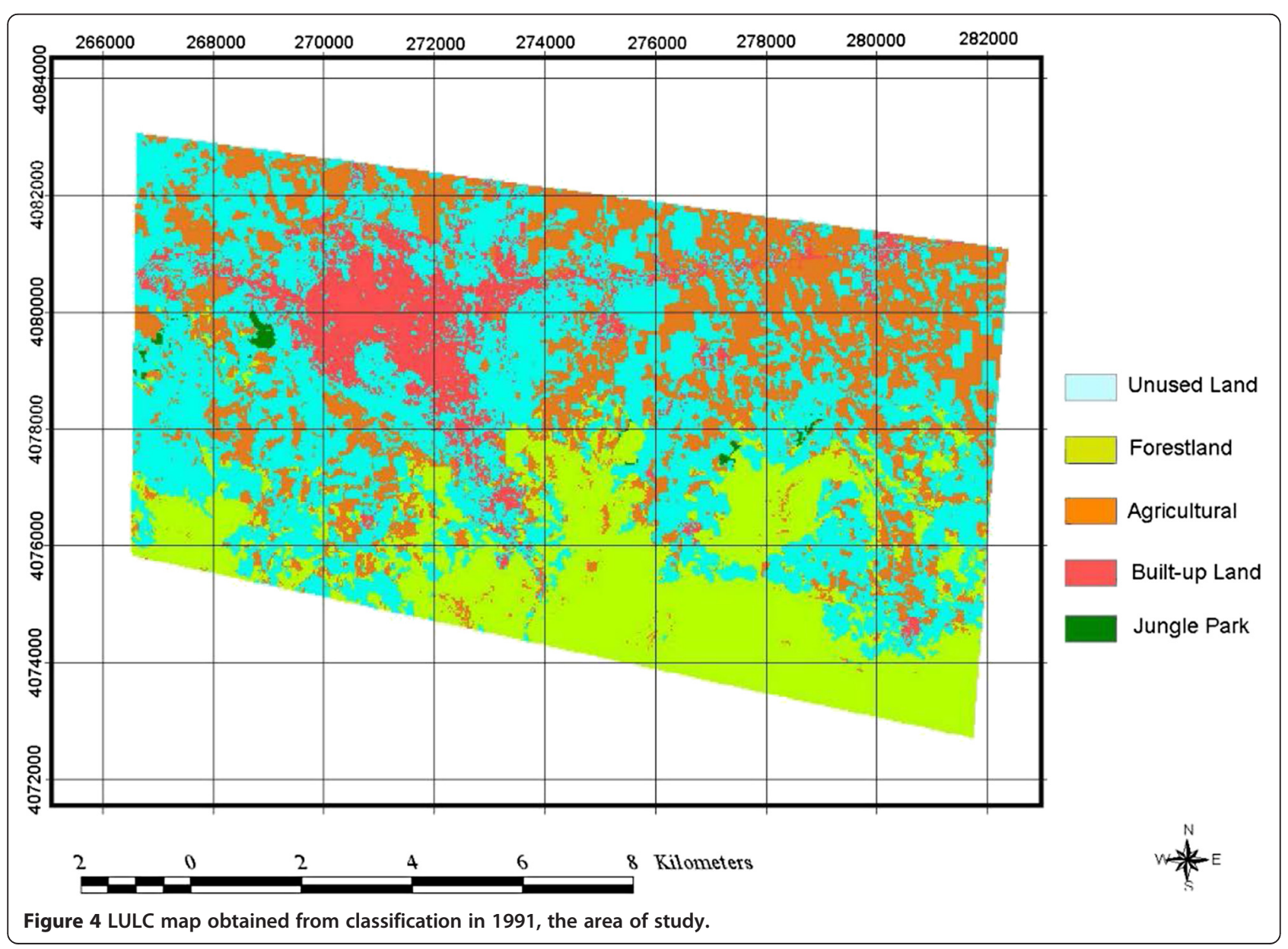




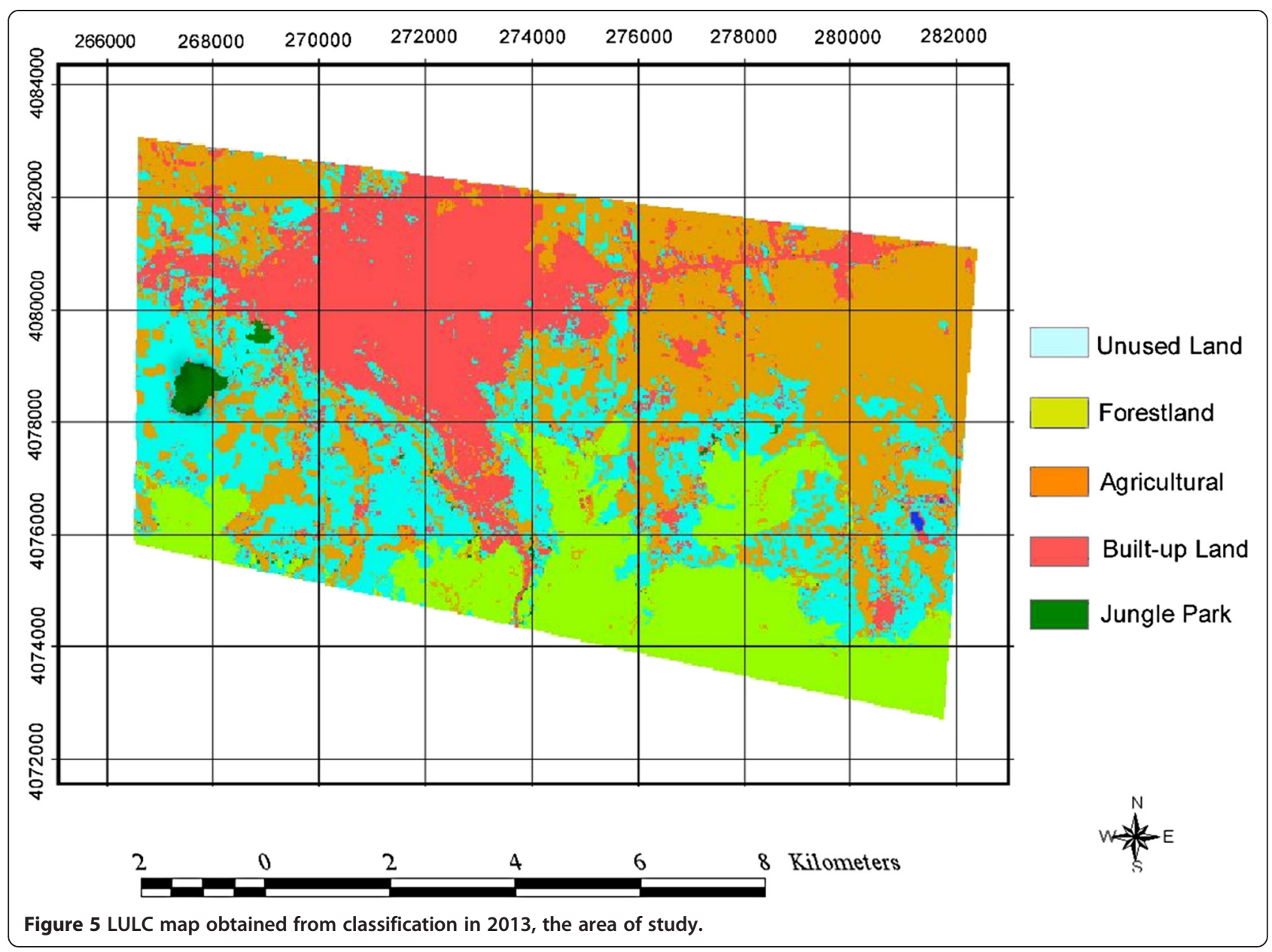

The system at time $2+t$ is $x t+2=x t+1 \cdot p=x t p p=x t p 2$. At time $t+k$, it is calculated as $x t+k=x t p k$ (Haibo et al., 2011; Meyn and Tweedie 2009). Since any change in the system eventually leads to a stable state (no perceptible change and stability over time), the state of the system in the steady state $(\pi)$ is calculable as Eq. 3:

$$
\pi=\pi \cdot P
$$

where $\pi$ is the potential vector state (in relative amounts) and $P$ is the transition matrix (Meyn and Tweedie 2009).

Table 2 The value of the classes of agricultural and forestlands

\begin{tabular}{lllll}
\hline Class & $\begin{array}{l}\text { Agricultural } \\
\text { Land size }\end{array}$ & $\begin{array}{l}\text { Percentage } \\
\text { of changes }\end{array}$ & Forestland size & $\begin{array}{l}\text { Percentage } \\
\text { of changes }\end{array}$ \\
\hline 1 & 94.21 & 63.14 & 54.18 & 94.34 \\
2 & 439.48 & 52.91 & 162.54 & 87.08 \\
3 & 754.91 & 46.68 & 255.49 & 81.84 \\
4 & 1120.35 & 38.94 & 746.32 & 69.64 \\
5 & 1643.44 & 31.08 & 1401.47 & 31.53 \\
6 & 8317.16 & 9.14 & 2764.79 & 7.71 \\
\hline
\end{tabular}

Since the type of LULC in the region evolves and changes, the stability of the approximate total area of land use and increases or decreases in the area of one type of land use will lead to an increase or decrease in other types. Possible transforms between the three major types of land use in the study area (forestland, agricultural, built-up areas) is shown in Figure 2 with six modes of conversion (forestland to built-up areas forestland to agriculture; agriculture to built-up areas; agriculture to forest; built-up areas to agriculture; built-up areas to forestland):

In practice, some conversions, like the conversion of built-up areas to agricultural or built-up areas to forestland, rarely occur. For the purposes of this study, three dominant states of conversion and transfer of land use is most common. Environmentally, the changes are alarming and must be modeled and studied. Figure 3 shows these three changes from forestland to built-up areas, forestland to agriculture and agriculture to built-up areas.

\section{Results}

Table 1 shows the classified images from 1991 and 2013. During this period, of the 2018.19 ha of forestland, 233.57 ha converted to agricultural land and 51.47 ha 
Table 3 The relationship between the conversion of agricultural land and distance from the built-up areas in the different classes

\begin{tabular}{llll}
\hline Class & $\begin{array}{l}\text { Distance from } \\
\text { Built-up areas }\end{array}$ & $\begin{array}{l}\text { Agricultural } \\
\text { land change }\end{array}$ & Forestland change \\
\hline 1 & 426.59 & 1864 & 5174 \\
2 & 1626.43 & 1826 & 2313 \\
3 & 2648.28 & 699 & 1212 \\
4 & 3294.76 & 43 & 139 \\
5 & 4763.24 & 9 & 11 \\
\hline
\end{tabular}

converted to built-up areas. From 3463.93 ha of agricultural land, 768.38 ha converted to built-up areas. The mean distance was calculated from built-up land use as a benchmark to evaluate and assess the process of change for agriculture and forestland use. Images from 1991 and 2013 show five classes and an average mean of 400 meters according to the processes of Figures 4 and 5 .

Table 2 shows the value of the six classes. In class 1 , for agricultural land for the smallest pixel size (94.21 units), the amount of change was $63.14 \%$. In class 6 , with the largest pixel size of 8317.16, the amount of change was $9.14 \%$. The southeastern areas and north of the city of Gorgan showed the most change. Distances further from the city, especially on both sides of the main highway has not been previously studied well. The determination coefficient between the sizes of the plots and the degree of conversion to built-up areas was estimated to be 0.93 . The smallest pixel size (54.18 units) for forestland showed a change of $94.34 \%$; for the maximum pixel size of 2764.79 , the amount of change was $7.71 \%$.
Table 3 shows the results of the relationship between the conversion of agricultural land and distance from the built-up areas in the different classes. The conversion rate is greater for classes nearer built-up areas and decreases as the distance increases. Table 3 shows that at an average distance of $426.59 \mathrm{~m}$ from built-up areas, the conversion rate in class 1 of agricultural land was 1864 pixels and for forestland was 5174 pixels and in class 2 was 1826 and 2313 pixels, respectively, illustrating the decreasing trend. The correlation rate between distance and conversion of agricultural land has a 0.86 coefficient of determination, which indicates a meaningful relationship between these two variables.

The results of Markov chain analysis indicates that when other terms and conditions are held constant, the current conversion rate from agricultural and forestland to built-up areas will decrease the amount of these types of land use $3.2 \%$ and $4.1 \%$, respectively in 10 years. The transfer and projected transfer between built-up areas, agricultural and forestland, respectively, for 1991 was $18.7 \%$, 39\%, and $42.3 \%$, for 2013 was $31.1 \%$, 34.9\%, and $35.5 \%$ and for 2023 will be $36.2 \%, 29.9 \%$, and $29 \%$. This represents an increase of the size of the urban area and a decrease in agricultural and forestland (Figures 6, 7 and 8).

Population growth and urban development that is rural in nature has increased the urbanization of agricultural and forestland. The influence of urban areas around and adjacent to commercial centers were studied for the province of Gorgan. Because the agricultural land in the area is of high grade and the forested areas have scenic beauty and resources, the conversion of agricultural and forestland around the urban center of the

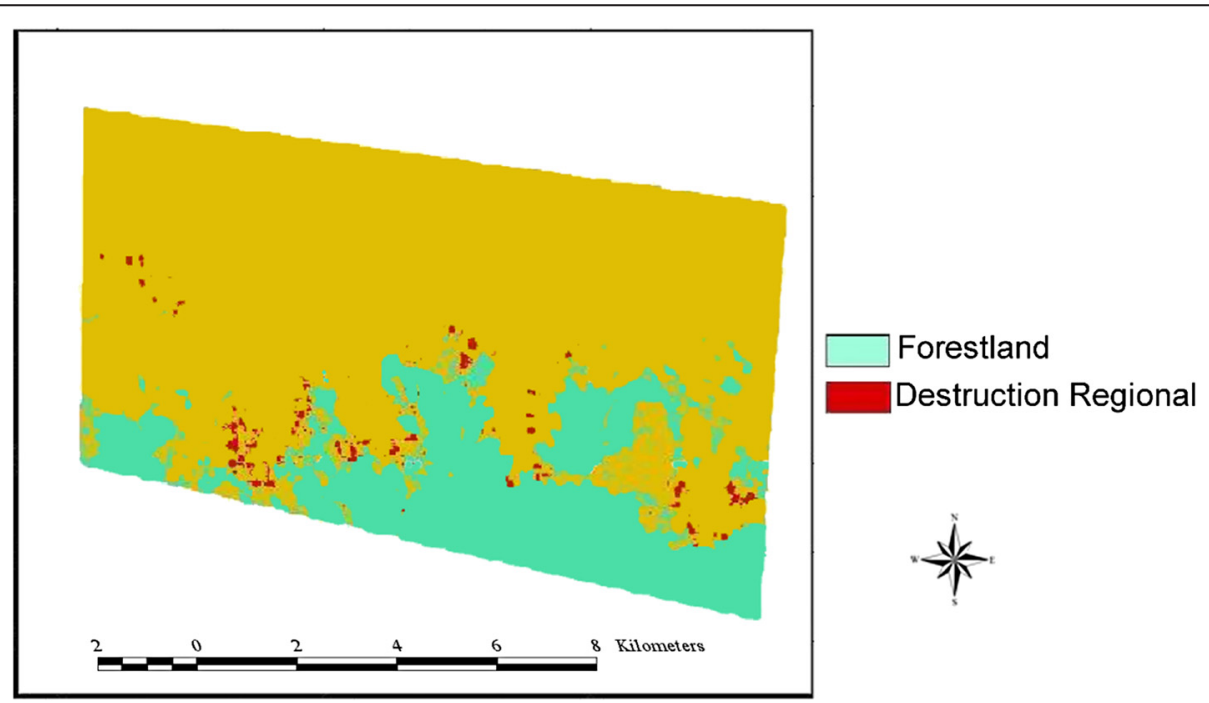

Figure 6 Forestlands of importance from the viewpoint of the risk of change into built-up areas within the next ten year period (20132023). 


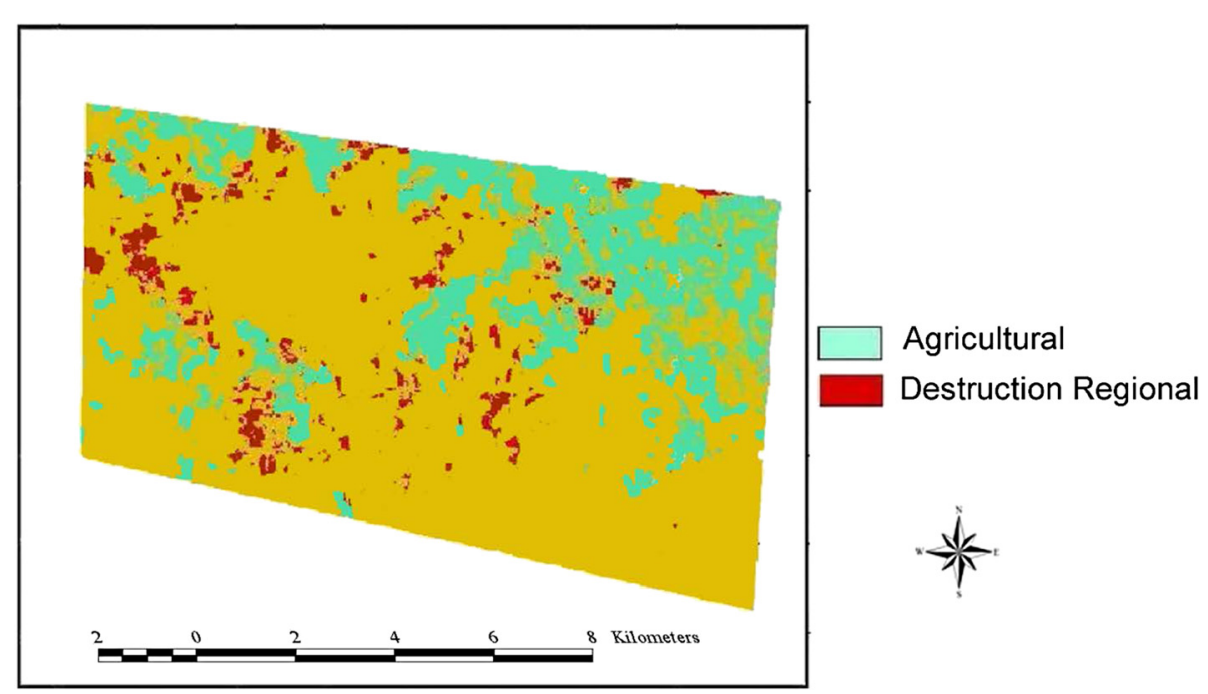

Figure 7 Agricultural areas of importance from the viewpoint of the risk of change into built-up areas within the next ten year period (2013-2023).

province cannot be equated with urban sustainable development indicators.

The relationship between the conversion of agricultural and forestland based on the size and distance from built-up areas was examined. Non-normative changes in vegetation and land use in built-up areas, agricultural and forestland, especially from 1997 onwards, indicate that the need to investigate the relationship between LULC changes in the area and assess the impact of urban development on these lands is twice what it would be for urban areas in less sensitive locations. The historic and confined nature of the city influenced the predictions for 2020. The predicted conversation to built-up areas from agricultural and forestland will increase 51.35 ha and 43.79 ha, respectively for this time period. The absence of linear growth and concentration of population in developing urban areas means that more accurate statistics on this conversion in the coming years will be greater than the estimated figures.

\section{Conclusion}

The employment of LULC change detection methods using satellite imagery and the analytical functions of distance and size in the GIS environment can help determine the process and pattern of significant changes in LULC. A good example of this is deforestation and the conversion of agricultural land to built-up areas. The identification of changes in the supervision and management of urban development should play a major role in the determination of principle policies for future land.

The horizontal expansion of the city of Gorgan includes factors such as military land use. The size of the land use

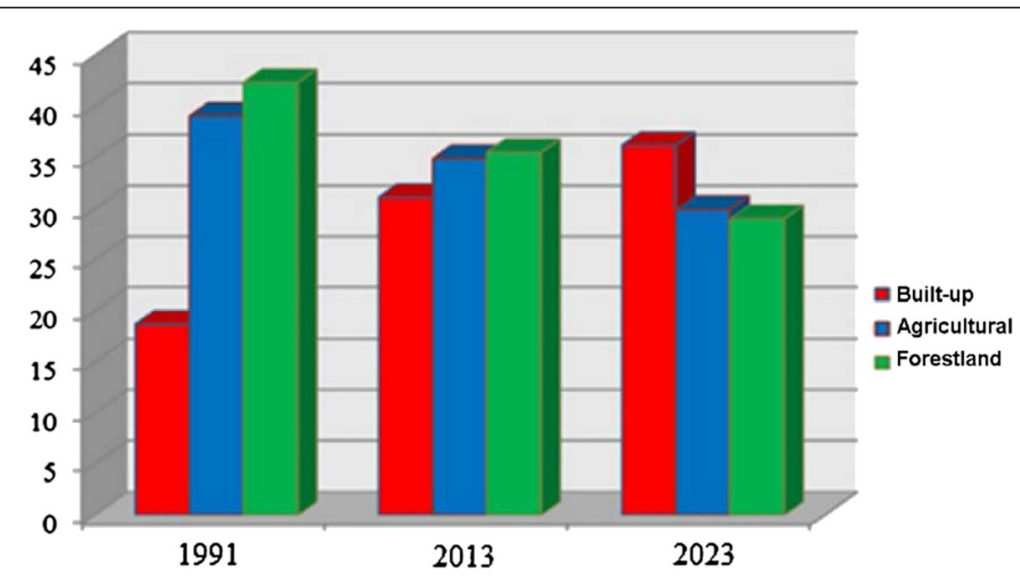

Figure 8 The comparison of the built-up areas, agricultural and forestlands percent trends in three periods of time. 
in 1976 was $284,500 \mathrm{~m}^{2}$, in 1994 was $395000 \mathrm{~m}^{2}$ and in 2006 was $419523.6 \mathrm{~m}^{2}$. Other factors influencing horizontal development of Gorgan are the change in land use and housing policies in the southern areas of the city, population migration after the 1979 revolution and ambiguity in the city codes and regulations after ratifications of the findings of the five-article plan for 2001 to 2006. The result was that more than 455 ha of agricultural and forestland to the south of the city was approved for urban development by the commission.

Mismanagement of tourist projects near forested areas in Naharkhoran, uncontrolled immigration, the high percentage of unnecessary LULC that increased the amount of unused land, urban and rural integration and the horizontal expansion of villages in Gorgan province are factors contributing to uncontrolled LULC.

The model results for 2013 showed a decrease in the level of forestland and agricultural land use from 1999, $5.1 \%$ and $3.6 \%$, respectively. It is imperative to find a solution to prevent this undesirable trend of conversion and destruction of forestland and agricultural land use. The present study presents an experimental model that clearly predicts the rates of LULC change and explains these changes. The model is experimental; thus, it is important to confirm how closely it has predicted the nature of development and changes over time. It must be determined how accurately past change can be used to predict future change.

The results of this study reveal the patterns and reasons behind changes in LULC in the past, present and future and provide an appropriate perspective for planners when managing land use. These results can be applied to assess the effects of development, evaluate the cumulative effects of projects, and identify vulnerable zones and aid in their reclamation. Finally, the results can be used to implement projects to decrease the effects of the destruction of forestland and agricultural land that will decrease greenhouse gas emissions and conserve the biodiversity of the area.

Gorgan is the provincial center and offers social, tourist, economic, industry attractions. It dominates the region because it is located between the flat plains to the north and the forested areas to the south and is adjacent to agricultural areas. The effects of city expansion are great and require systematic and planned development of the city. Programs to monitor activities that exploit forested areas and expand construction in the region, especially for the tourist and recreational area in Naharkhoran, is essential. Land use planning must take into consideration to prevent the destruction of agricultural land and forested areas around the city. This type of planning will affect the future of agricultural production, timber production, and recreational and leisure activities. It is evident that the regulation and monitoring of urban development projects and settlements must be the result of careful and consistent planning.

\section{Competing interests}

The authors declare that we have no competing interests.

\section{Authors' contributions}

$\mathrm{JM}, \mathrm{AH}$ and $\mathrm{AN}$ contributed equally to writing the article. All authors read and approved the final manuscript.

\section{Author details}

${ }^{1}$ Department of Geography, University of Golestan, Gorgan, Iran.

${ }^{2}$ Department of Geography and Urban Planning, University of Tehran, Tehran 1417854151, Iran. ${ }^{3}$ Department of Geography and Urban Planning, University of Tarbiyat Modares, Tehran, Iran.

Received: 6 October 2014 Accepted: 27 January 2015

Published online: 24 February 2015

\section{References}

Antwi EK, Boakye-Danquah J, Asabere SB, Takeuchi K, Wiegleb G (2014) Land cover transformation in two post-mining landscapes subjected to different ages of reclamation since dumping of spoils. Springerplus 3(1):702

Aurbacher J, Dabbert S (2011) Generating crop sequences in land-use models using maximum entropy and Markov chains. Agr Syst 104(6):470-479

Balthazar V, Vanacker V, Lambin EF (2012) Evaluation and parameterization of ATCOR3 topographic correction method for forest cover mapping in mountain areas. Int J App Earth Obs Geoinf 18:436-450

Barsimantov J, Navia Antezana J (2012) Forest cover change and land tenure change in Mexico's avocado region: Is community forestry related to reduced deforestation for high value crops? Appl Geogr 32(2):844-853

Bhatta B, Saraswati S, Bandyopadhyay D (2010) Quantifying the degree-of-freedom, degree-of-sprawl and degree-of-goodness of urban growth from remote sensing data. Appl Geogr 30:96-111

Carvalho Ribeiro S, Migliozzi A, Incerti G, Pinto Correia T (2013) Placing land cover pattern preferences on the map: Bridging methodological approaches of landscape preference surveys and spatial pattern analysis. Landsc Urban Plan 114:53-68

Chen H, Liang X, Li R (2013) Based on a multi-agent system for multi-scale simulation and application of household's LUCC: a case study for Mengcha village, Mizhi county, Shaanxi province. Springerplus 2(Suppl 1):S12

Eksler $V$ (2008) Exploring spatial structure behind the road mortality of regions in Europe. Appl Spatial Anal Policy 1(2):133-150

Feitosa RQ, da Costa GAOP, Mota GLA, Feijó B (2011) Modeling alternatives for fuzzy Markov chain-based classification of multitemporal remote sensing data. Pattern Recogn Lett 32(7):927-940

Fonji SF, Taff GN (2014) Using satellite data to monitor land-use land-cover change in North-eastern Latvia. Springerplus 3(1):61

Geography Organization, 2013. Map Topography, Scale 1:50000, publication of national geography organization, Iran.

Gong W, Yuan L, Fan W, Stott P (2015) Analysis and simulation of land use spatial pattern in Harbin prefecture based on trajectories and cellular automataMarkov modelling. Int J Appl Earth Obs Geoinf 34:207-216

Gorgan Watershed Management, 2001. Guideline of land-use maps preparation using interpretation of satellite data. 1st Edn. publication of forest, rangeland and watershed management, Tehran.

Guan D, Li H, Inohae T, Su W, Nagaie T, Hokao K (2011) Modeling urban landuse change by the integration of cellular automaton and Markov model. Ecol Model 222(20):3761-3772

Haibo Y, Longjiang D, Hengliang G, Jie Z (2011) Tai'an land use analysis and prediction based on RS and Markov model. Procedia Environ Sci 10:2625-2630

Hosseini A, Shabanifard M, Rashidi M, Saiydzade MR (2010) Distribution and Determining of Urban Sprawl in Kerman with Emphasis on Kariz Water System. Physics Int 1(1):9

Iran Statistical Center, 2013. Golestan Province Statistic Books. publication of Iran statistical center, Iran.

Kamusoko C, Aniya M, Adi B, Manjoro M (2009) Rural sustainability under threat in Zimbabwe-simulation of future land use/cover changes in the Bindura district based on the Markov-cellular automata model. Appl Geog 29(3):435-447

Klosterman RE (2008) Modelling Land-use Change: Progress and Applications (GeoJournal Volume 90). Appl Spatial Anal Policy 1(2):151-152, Eric Koomen, John Stillwell, Aldrik Bakema, and Henk J. Scholten, eds

Lillesand TM, Kiefer RW, Chipman JW (2008) Remote Sensing and Image Interpretation, 6th edn. John Wiley and Sons, Inc., New York. ISBN 0470052457 
Mabwoga SO, Thukral A (2014) Characterization of change in the Harike wetland, a Ramsar site in India, using landsat satellite data. SpringerPlus 3(576): 1-11.

Meyn SP, Tweedie R L (2009) Markov chains and stochastic stability. Cambridge University Press. United Kingdom.

Mirali-Katouli J (2002) The Process of Supply and its Role in Iran Urban Development Case: Gorgan. Dissertation Ph.D, Tarbiat Modares University, Tehran

Nanda A, Yeh JH (2014) Spatio-temporal diffusion of residential land prices across Taipei regions. Springer Plus 3(1):505

Palermo PC (2014) What ever is happening to urban planning and urban design? Musings on the current gap between theory and practice. City Territory Architecture 1(1):1-9

Pathirana A, Denekew HB, Veerbeek W, Zevenbergen C, Banda AT (2014) Impact of urban growth-driven landuse change on microclimate and extreme precipitation-A sensitivity study. Atmos Res 138:59-72

Peled A, Gilichinsky M (2013) GIS-driven classification of land use using IKONOS data and a core national spatial information database. Appl Geomatics 5(2):109-117

Pelorosso R, Leone A, Boccia L (2009) Land cover and land use change in the Italian central Apennines: A comparison of assessment methods. Appl Geogr 29(1):35-48

Plan and Architect Iran Consulting Engineers, 2006. Comprehensive Plan of Gorgan City. publication of ministry of roads \& urban development, Iran.

Richards JA, Jia X (2006) Remote sensing Digital image Analysis an Introduction. Birkhäuser, Germany

Schott JR (2007) Remote sensing. Oxford University Press. United Kingdom.

Shahkohi I (1999) A Look at Natural Outlook of Golestan Province, vol 10. Sepehr J, Tehran, pp 12-24

Tan R, Liu Y, Zhou K, Jiao L, Tang W (2015) A game-theory based agent-cellular model for use in urban growth simulation: A case study of the rapidly urbanizing Wuhan area of central China. Comput Envir Urban Syst 49:15-29

Thompson DK, Waddington JM (2014) A Markov chain method for simulating bulk density profiles in boreal peatlands. Geoderma 232:123-129

Torre A, Melot R, Magsi H, Bossuet L, Cadoret A, Caron A, Kolokouris O (2014) Identifying and measuring land-use and proximity conflicts: methods and identification. Springerplus 3(1):1-26

Trincsi K, Pham TTH, Turner S (2014) Mapping mountain diversity: Ethnic minorities and land use land cover change in Vietnam's borderlands. Land Use Policy 41:484-497

Varaste Moradi M (1997) Modeling of Land use changes using of multi-epoch images and GIS. Dissertation Ph.D, Tarbiat Modares University Press, Tehran

Yang X, Zheng XQ, Lv LN (2012) A spatiotemporal model of land use change based on ant colony optimization, Markov chain and cellular automata. Ecol Model 233:11-19

Ye Y, Fang X (2011) Spatial pattern of land cover changes across Northeast China over the past 300 years. J Hist Geogr 37(4):408-417

Zhang $X$, Kang T, Wang H, Sun Y (2010) Analysis on spatial structure of landuse change based on remote sensing and geographical information system. Int Appl Earth Obs Geoinf 12:S145-S150

\section{Submit your manuscript to a SpringerOpen ${ }^{\circ}$ journal and benefit from:}

- Convenient online submission

- Rigorous peer review

- Immediate publication on acceptance

- Open access: articles freely available online

- High visibility within the field

- Retaining the copyright to your article

Submit your next manuscript at $>$ springeropen.com 